\title{
Potential use of clay from Burkina Faso as filler in rubber production
}

\author{
Mohamed SEYNOU ${ }^{1 *}$, Joachin ZOUNGRANA ${ }^{2}$, Moumouni SAVADOGO ${ }^{1}$, \\ Remi OUATTARA ${ }^{2}$ and Raguilnaba OUEDRAOGO ${ }^{1}$ \\ ${ }^{1}$ Laboratoire de Physico-Chimie et de Technologie des Matériaux (LPCTM), UFR/ Sciences Exactes et \\ Appliquées, Université de Ouagadougou, 03 B.P. 7021 Ouagadougou 03, Burkina Faso. \\ ${ }^{2}$ Société Africaine de Pneumatiques (SAP) 01 BP 389 Bobo-Dioulasso 01, Burkina Faso. \\ *Corresponding author; E-mail: seynou1mohamed@yahoo.fr
}

\begin{abstract}
A raw clay materials deposit in Burkina Faso have been characterized by X-ray diffraction (XRD), scanning electron microscopy (SEM) and chemical analysis to evaluate their potentialities to be used in rubber compounds production as filler. The samples are composed principally by kaolinite, illite and quartz. The rubber compounds have been done in open two-roll mill at room temperature and tested for cure characteristic $\left(\mathrm{t}_{\mathrm{s}} 5, \mathrm{t}_{\mathrm{c}} 90\right)$, mineralogical composition by XRD, microstructure by SEM and mechanical properties (Elongation at break, Tear strength, tensile strength, hardness shore A and modulus). The cure characteristics of the rubber compounds formulated with the sample are feeble than those made with commercial kaolin (control). The mechanical properties are in general, except the elongation at break, for the sample lowest than those of control. However the different values obtained with the sample are not far to those obtained with commercial kaolin. The different samples can then be used as filler in rubber production after a pre-treatment to reduce the impurities.
\end{abstract}

(C) 2014 International Formulae Group. All rights reserved.

Keywords: Raw clay materials, rubber, rheology.

\section{INTRODUCTION}

Natural rubber (NR) is not ready for use. It requires different preparation processes before industrial use. Some components such as carbon black $(\mathrm{CB})$, silica $(\mathrm{S})$ and clay mineral $(\mathrm{CM})$ are always introduced to achieve the desired mechanical properties such as modulus, tensile strength, tearing and fatigue resistance and so on (Valadares et al., 2006 ; Yijing et al., 2012 ; Xiaohui et al., 2012). These additives materials (CB, S, and $\mathrm{CM}$ improve the mechanical, thermal, optical, gas permeability and electrical properties of natural rubber to meet the demands of practical application. In the last decades, clay minerals appeared greatly attractive as they are largely available as natural minerals, have a safe toxicological profile and bring about a significant improvement of the physical, mechanical and barrier properties of polymer even at very low concentration (Lucia et al., 2012). Montmorillonite has been largely used in natural rubber reinforcing (Lucia et al., 2012). 
It is today, the same case for kaolin which is greatly used in tube and tire production. The use of kaolin in rubber reinforcing depends on its mineralogical, chemical, physical properties (morphology and particle size) and its thermal behavior. The incorporation of kaolin in the natural rubber affects it vulcanization kinetic and influence then it mechanical properties (Sepehri et al., 2012; Saritha et al., 2012).

In Burkina Faso, the African Society of Tires (in French "Société Africaine de Pneumatiques SAP"), located in BoboDioulasso produced for decades, tires and tubes for bicycles and motorcycles. The tires and tubes produced by the African Society of Tires (SAP) with high quality are facing harsh competition with products coming from developed countries. The African Society of Tires products are more expensive than the imported products. This situation is caused by the import of some raw materials such as natural rubber (latex) from Ghana and Ivory Coast and kaolin from France. For example, the African Society of Tires imports an average 120 tons per year of kaolin. However, many sites of potential kaolin material exist in Burkina Faso and could be used by African Society of Tires, which will make its products more competitive. Despite the many studies conducted on the characterization and valuation of clay materials of Burkina Faso, its application in the rubber reinforcing has not yet been performed.

The aim of this work is the characterization of some clays sites in Burkina Faso to assess their potential to be used as filler in rubber production. The paper is then composed of two parts. The first part concerns the physico-chemical, mineralogical, thermal and microstructural characterization of clay designated for this purpose. The second part is devoted to assessing the technological parameters as viscosity, the torque and mechanical properties of rubber loaded with clay.

\section{MATERIALS AND METHODS Materials}

The used raw clay materials, referenced M1, M2, M3 and M4, are deposit in central region of Burkina Faso at $125 \mathrm{~km}$ north of Ouagadougou, not far from Kongoussi Figure 1. The reference raw material is industrial kaolin used by the African Society of Tires society in the tires and tubes production. It is afforded by France.

The Natural Rubber of type SMR-20 was purchased from Gold Coast Latex Industry. Stearic acid, zinc oxide $(\mathrm{ZnO})$, element sulfur (S), benzothiazyl disulfide, phenyl beta naphthyl amine and the iron were all commercial grades and were purchased from Chemmin Co. Ltd. Zinc oxide and stearic acid are used as activators, benzothiazyl disulfide is the accelerator, the phenyl beta naphthyl amine is the antioxidant and the element sulfur is a crosslinker.

\section{Raw clay characterization}

The X-ray diffraction (XRD) patterns were performed with a SIEMENS diffractometer D50 functioning at $40 \mathrm{kV}$ and $50 \mathrm{~mA}$. The used wavelength is $\mathrm{CuK} \alpha=1.54$ $\AA$.

The chemical analyses of major, minor and trace elements were carried out using ICP-AES and ICP-MS. The samples were burnt by $\mathrm{LiBO}_{2}$ followed by dissolution by $\mathrm{HNO}_{3}$.

The microstructure of the powder was observed with electron microscopy HITACHI scanning type SC-2500. Au / Pd were used for metalizing the different samples.

The mineralogical composition was derived from the XRD results and the chemical composition using the formula proposed by Yvon et al. (1982).

\section{Preparation of rubber compounds}

The different ingredients used in the rubber compounds are given in Table 1. All the compounds contained the same amount of 
ingredients. The difference between the mixtures is the nature of raw clay material which is used for reinforcing. The different ingredients with the natural rubber (NR) without the accelerators (benzothiazyl disulfide) are mixed in open two-roll mill at room temperature for $15 \mathrm{~min}$. After that, the obtained compound is remixed with the accelerator for $5 \mathrm{~min}$.

\section{Testing of rubber compounds}

The cure characteristics as scorch time ts5, optimum cure time tc90, minimum torque $\mathrm{M}_{\mathrm{L}}$, and maximum torque $\mathrm{M}_{\mathrm{H}}$ and torque difference $\Delta \mathrm{M}$ were determined using a moving Oscillating Die Rheometer GT GOETECH 7070S2.
For the determination of mechanical parameters, the different mixtures have been vulcanized in hot temperature at $170{ }^{\circ} \mathrm{C}$ for the optimum cure time tc90. The apparatus used is AI-7000M GOETECH Universal Testing Machine. Tensile and tear tests were performed with standards dumbbell shapes specimens at room temperature at a rate of $500 \mathrm{~mm} / \mathrm{min}$. For each sample, five parallel measurements were carried out and the average value was taken. Stress at 100 and $300 \%$ elongation, stress at break and elongation at break were measured according to Standards ISO 37:2005. The hardness of vulcanizates was measured using a Shore A durometer according to ISO 7619-1.

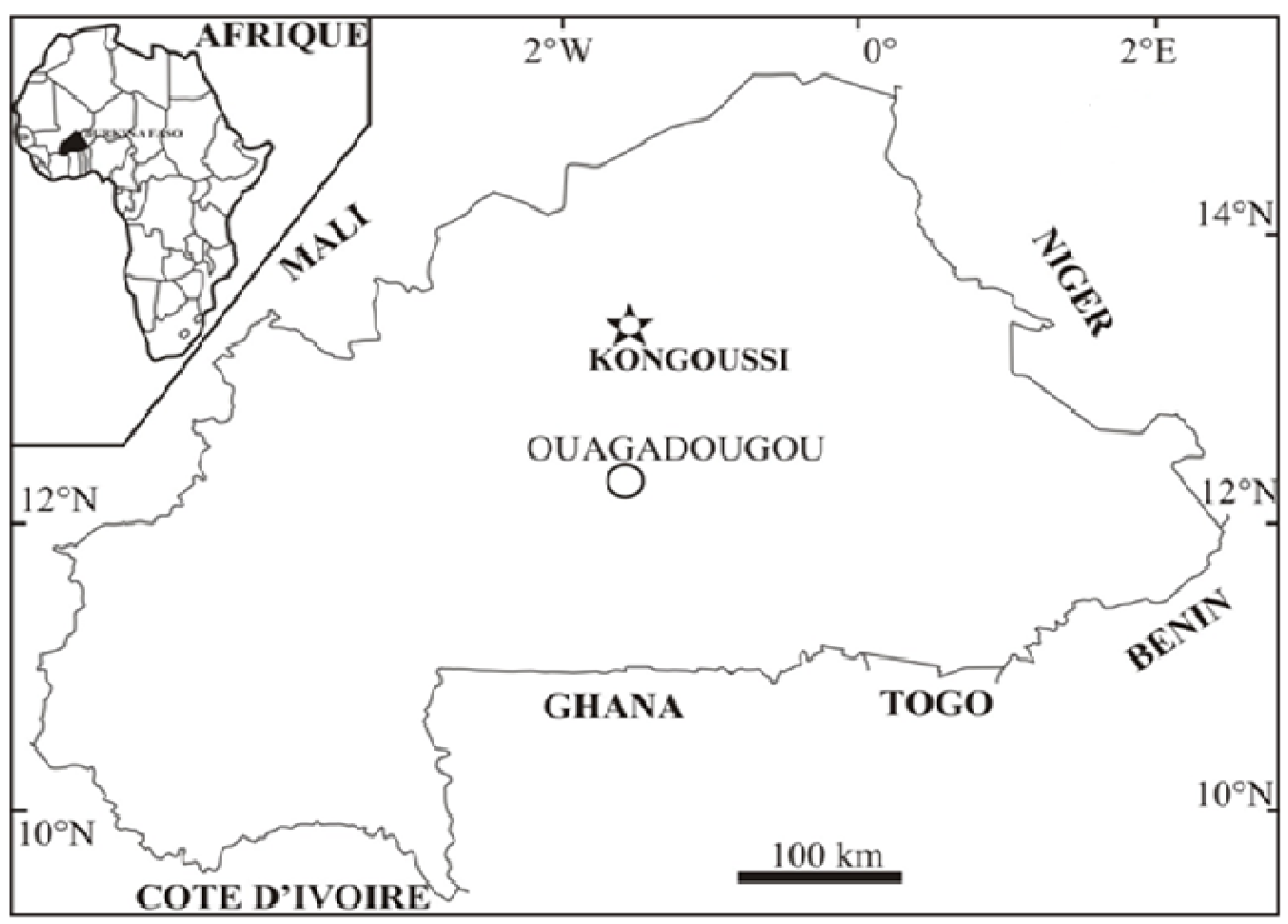

Figure 1: Location of the four raw clay materials. 
Table 1: Composition of rubber compounds.

\begin{tabular}{lc}
\hline Component & $\begin{array}{c}\text { Amount } \\
\text { (Parts per hundred parts of rubber) }\end{array}$ \\
\hline Natural rubber & 100 \\
Raw clay material & 50 \\
Zinc oxide & 5 \\
Stearic acid & 1 \\
Sulfur & 1.5 \\
Benzothiazyl disulfide & 1.5 \\
Phenyl beta naphthyl amine & 1 \\
Iron & 5 \\
\hline
\end{tabular}

\section{RESULTS AND DISCUSSION}

Raw clay materials characterization

Figure 2 give the $\mathrm{X}$-ray diffraction patterns of samples. The main mineral phases are kaolinite $\left(\mathrm{Al}_{2} \mathrm{Si}_{2} \mathrm{O}_{5}(\mathrm{OH})_{4}\right)$, quartz $\left(\mathrm{SiO}_{2}\right)$ and illite $\left(\left(\mathrm{K}, \mathrm{H}_{3} \mathrm{O}\right) \mathrm{Al}_{2} \mathrm{Si}_{3} \mathrm{AlO}_{10}(\mathrm{OH})_{2}\right)$.

The chemical compositions of samples are presented in Table 2-a. The main oxides are $\mathrm{SiO}_{2}$ and $\mathrm{Al}_{2} \mathrm{O}_{3}$. According to previous study, the chemical composition of M1, M3 and M4 are in the ranges of sandy-kaolin and that of M2 are close to fine kaolin. In addition to the major oxides, the samples contain $\mathrm{K}_{2} \mathrm{O}$ due to illite presence. We also note the presence of iron oxide $(3.71 \%)$ in $\mathrm{M} 2$ which is responsible for its brown color. For the trace elements (Table 2-b), zircon is the most important in all the samples. M2 contains $\mathrm{Zn}$ in trace proportion contrary to the other where this element is absent.

Chemical analysis and mineralogical analyses permit to assess the relative amounts of minerals phases for samples. The results are reported in Table 3. M2 contains the high amount of kaolinite. The three other samples have high quartz content.

The SEM images (Figure 3) examination show that M2 and M4 consist in sheet containing important platelets characteristics of kaolinite. The platelets in great numbers for M2 corroborate the results of mineralogical composition. The shape of platelets contained in M4 are more regular hexagonal and show the fact that kaolinite in M4 is more ordered than the other samples.
The samples M1 and M3 are composed of a small amount of platelets which are surrounded by particles with high size corresponding to quartz.

\section{Mineralogical and microstructure characterization of rubber compounds}

The infrared spectra of rubber compounds before vulcanization are given by Figure 4 . The kaolinite hydroxyl are present around $3700-3620 \mathrm{~cm}^{-1}$ but have strongly affected. The external hydroxyls bands at 3699 and $3567 \mathrm{~cm}^{-1}$ are transformed respectively at 3691 and $3650 \mathrm{~cm}^{-1}$. The displacement is due to intercalation of clay interlayer by organic compounds provided by natural rubber. This intercalation is confirmed by the displacement of $\mathrm{Al}-\mathrm{OH}$ bands which appears at $913 \mathrm{~cm}^{-1}$ in raw clays and $937 \mathrm{~cm}^{-1}$ in the rubber compounds. The bands at 2915 and $2860 \mathrm{~cm}^{-1}$ are assigned to $\mathrm{CH}_{2}$ symmetric stretching and $\mathrm{CH}_{2}$ asymmetric stretching. The wave numbers of $\mathrm{CH}_{2}$ bands inform that we have well-ordered layers such as crystalline paraffin (Joshi et al., 2012; Yehia et al., 2012). The band at $1442 \mathrm{~cm}^{-1}$ is characteristic of $\mathrm{C}=\mathrm{C}$ vibration. The presence of quartz $(\mathrm{Si}-\mathrm{O}-\mathrm{Si})$ is shown by the bands at 466 , and $692 \mathrm{~cm}^{-1}$.

The SEM images of rubber compounds before vulcanization are showed by the Figure 5. The SEM image of M2 shows a better dispersion of this raw clay in the rubber matrix. The other (M1, M3 and M4) are characterized by an important cluster and 
presences of particles with high size corresponding to the quartz. The mixture M2 has the similar microstructure with the control and seems to be more compatible with the rubber matrix.

\section{Cure characterization}

The cure characteristic parameters deduced in Figure 6 are collected in Table 4. The torque difference is an indicator of crosslink density of the vulcanizates. The torque difference for samples is higher than the control. The increase of torque difference caused the decrease of the compounds viscosity. The decrease of viscosity caused the increase of crosslink density. These results are corroborated by the scorch time and optimum time for the entire samples which are lowest than the values of control. The control with high amount of kaolinite has an important amount of hydroxyls which react with activator as accelerator and reduce then the number of active sulfurating agents which are necessary for vulcanization (Rattanasom et al., 2009). The obtained optimum cure time tc90 are in the same range of those obtained by Rattanasom et al. (2009) when he uses calcined clay at different amount as filler in natural rubber. However, the obtained torque differences are very high than those obtained by the same author.

\section{Mechanical properties}

The different mechanical properties such as elongation at break, cut tensile strength, tear strength, modulus (at $100 \%$, $300 \%$ ) and hardness shore A are represented respectively by the Figures 7, 8, 9, 10 and 11 .

The elongation at break for M2 and M4 are higher than the control and the two others. The different values of elongation at break are similar to those found by Valadares et al. (2006) when he uses $33 \%$ of carbon black as filler, but high than those found by Rattanasom et al. (2009). The different results show the relation between the elongation at break and the nature of filler. As the others mechanical properties, the elongation is influenced by the particle size of filler. The small sizes contribute to improve the reinforcing properties of filler. The cut tensile strengths for the entire samples are lowest than the control. The modulus at 100 and $300 \%$ for the rubber compounds are feeble than the control value. M1 presents a value not far from control.

The different compounds have a similar hardness slightly less than that of control. The elongation depends on the dispersion of clay on the rubber matrix. For the better dispersion (consistency) as shown by SEM image, the elongation is high. Except M3, the three other rubber compounds have a similar maximal tensile strength, slightly less than the control.

Figures 12 and 13 shows the evolution of some mechanical properties with the kaolinite amount. The $300 \%$ modulus and tensile strength increase with kaolinite amount up to $34 \%$ before its decrease with the kaolinite percentage.

The high amount of kaolinite does not benefit to modulus and tensile strength. The elongation at break decreases with kaolinite percentage up to $34 \%$ and increase after. Contrary to elongation, the tear increases up to $34 \%$ and decreases after. In general, the $34 \%$ of kaolinite give the better mechanical properties. According to Yijing et al. (2010) at low content of nanoclay, the clay layer could be easily exfoliated into single platelets which preferred to orient at the direction of stretching and promoted the strain - induced crystallization behavior of rubber chains and increase then the mechanical resistance (modulus and tensile strength).

For all mechanical properties in general, the values are slightly lower than that of control. The difference can be justified by the nature of the raw materials used in these tests. The important amount of quartz in the sample and some impurity influence the mechanical properties. 


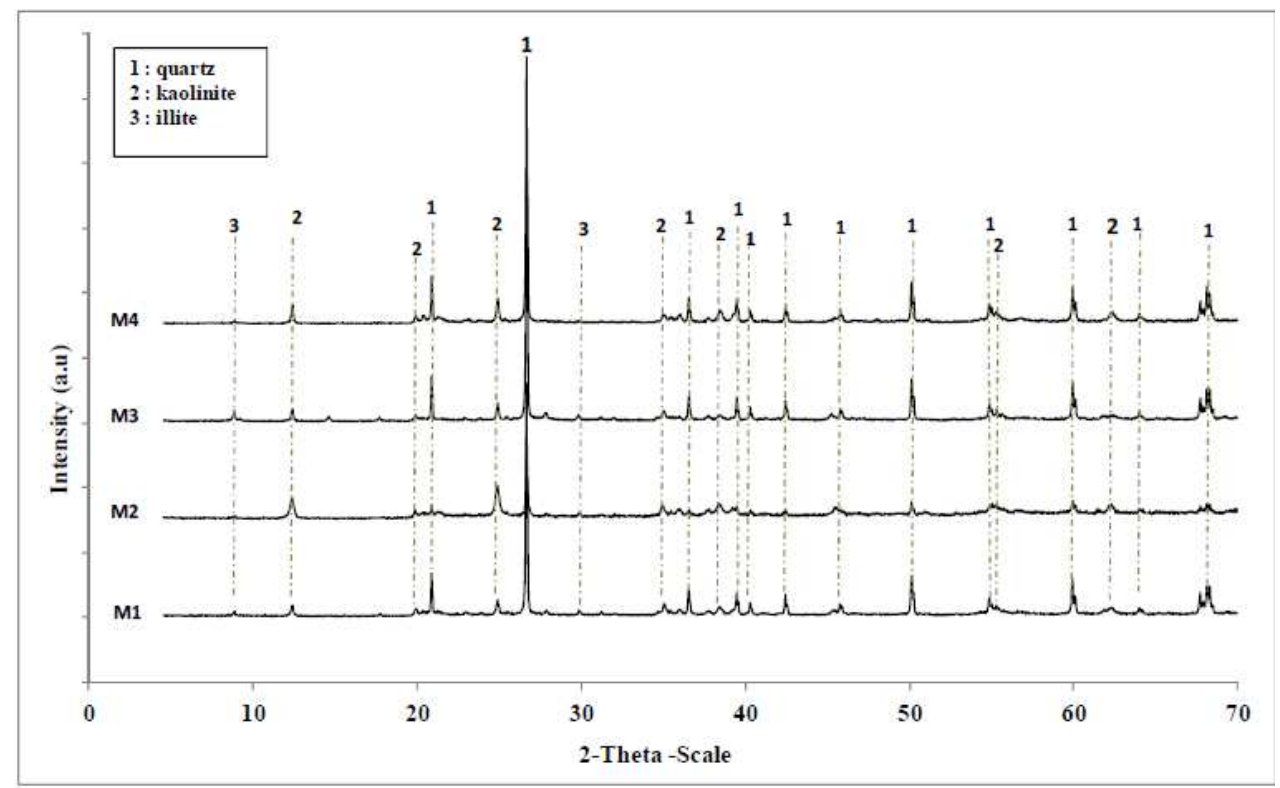

Figure 2: X-ray diffraction of raw clay materials.
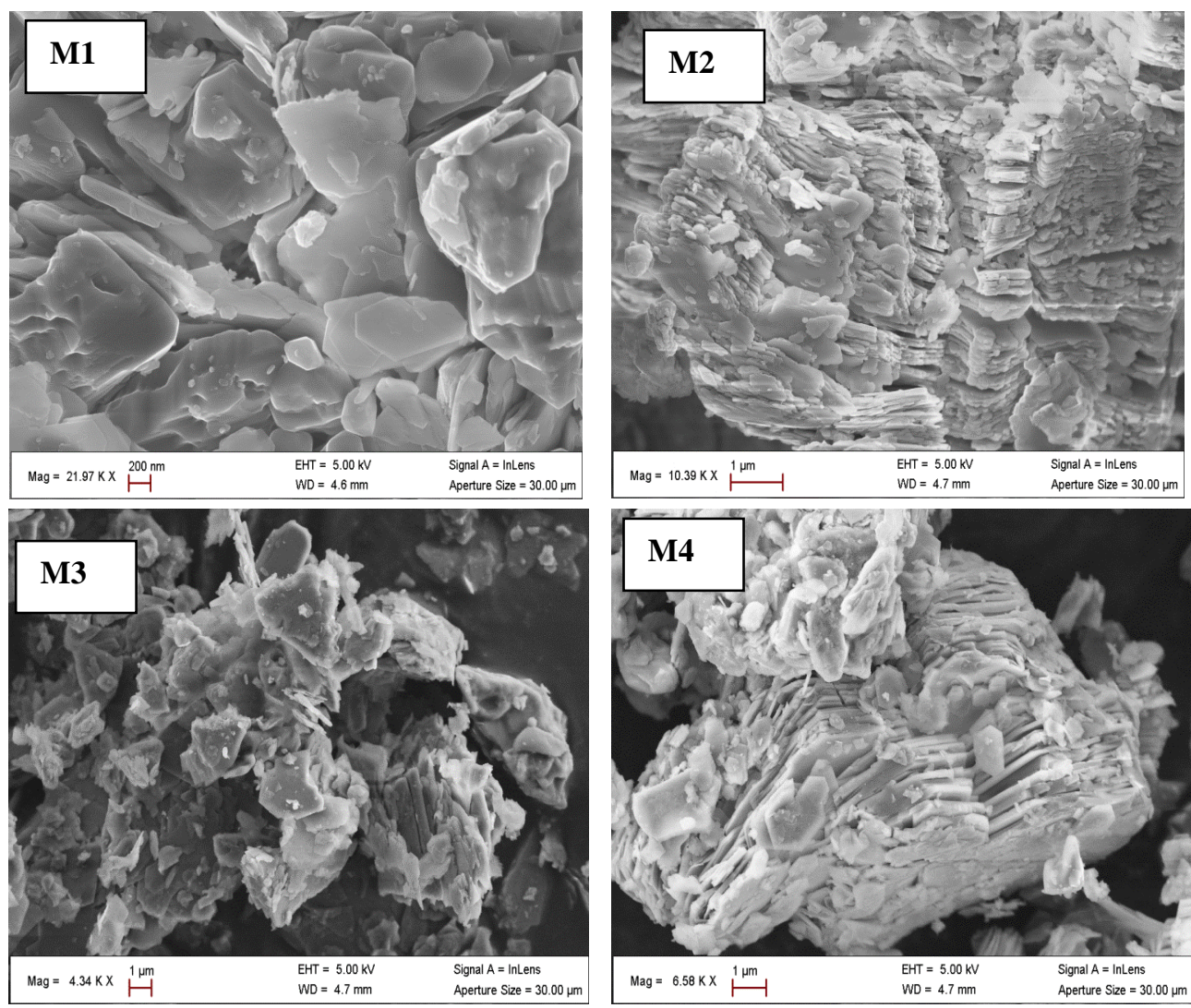

Figure 3: SEM image of raw clays materials. 

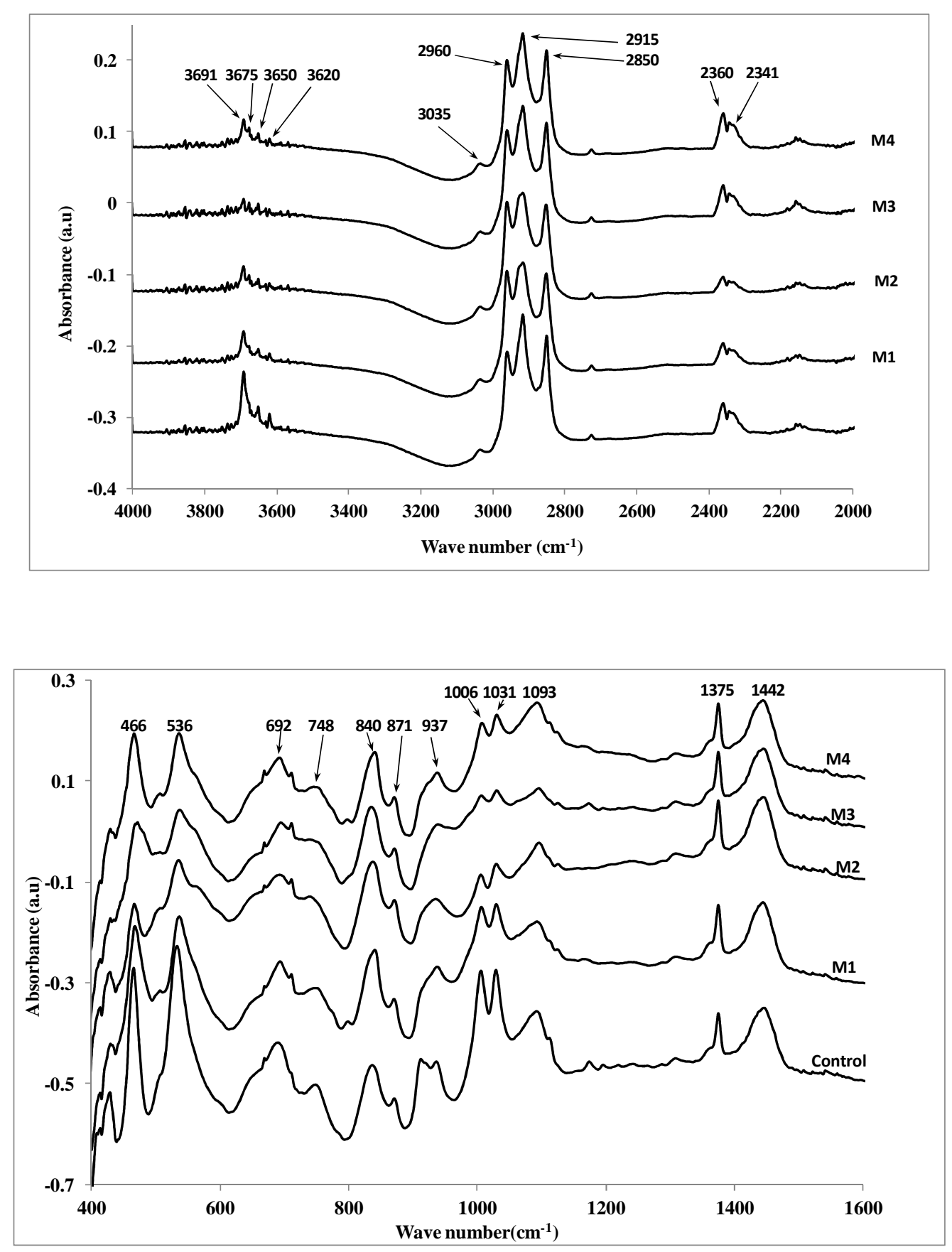

Figure 4: Infrared spectra of rubber compound before vulcanization. 

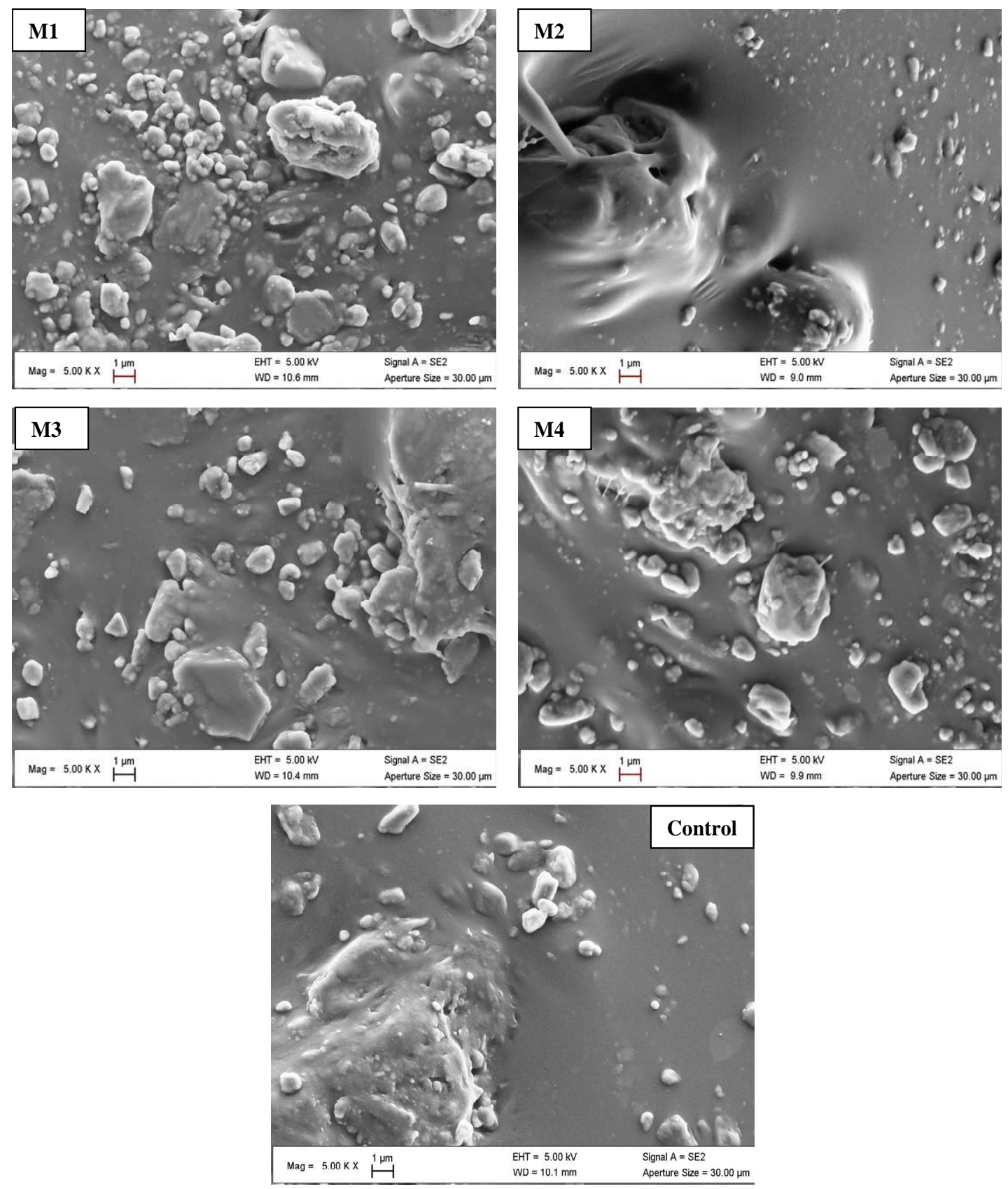

Figure 5: SEM image of rubber compound before vulcanization. 


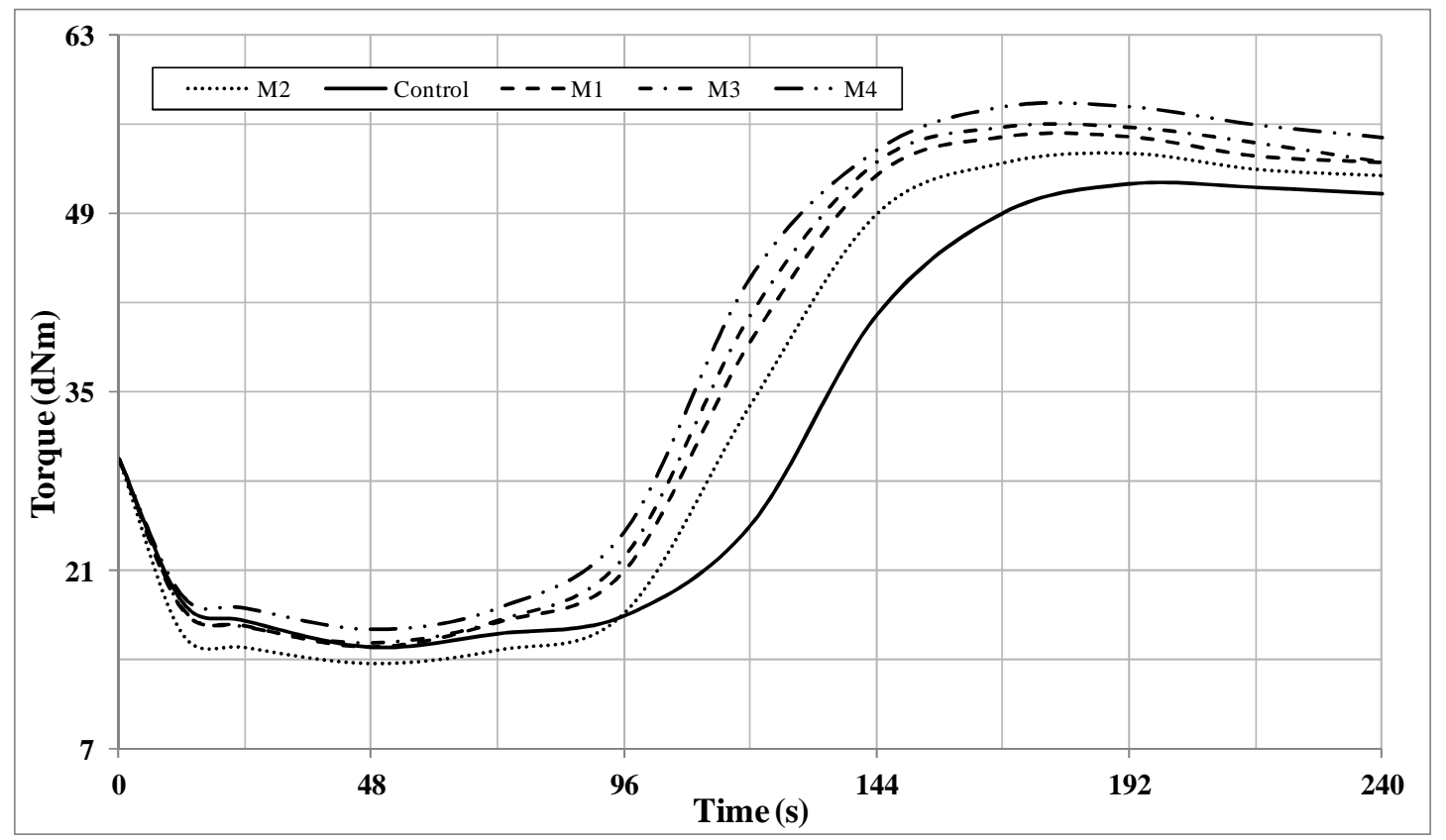

Figure 6: Cure curves of rubber compounds.

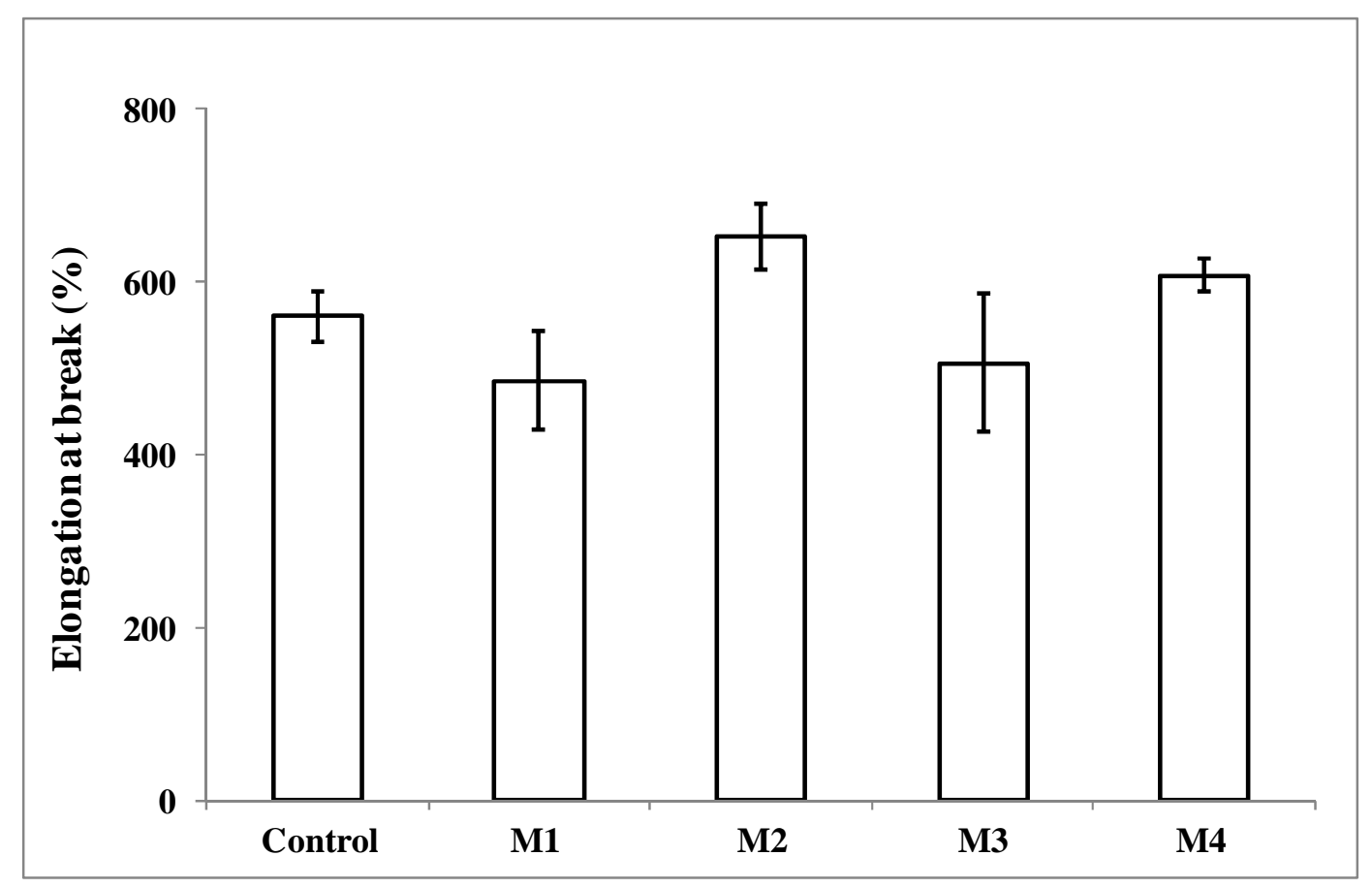

Figure 7: Elongation at break of vulcanized products. 


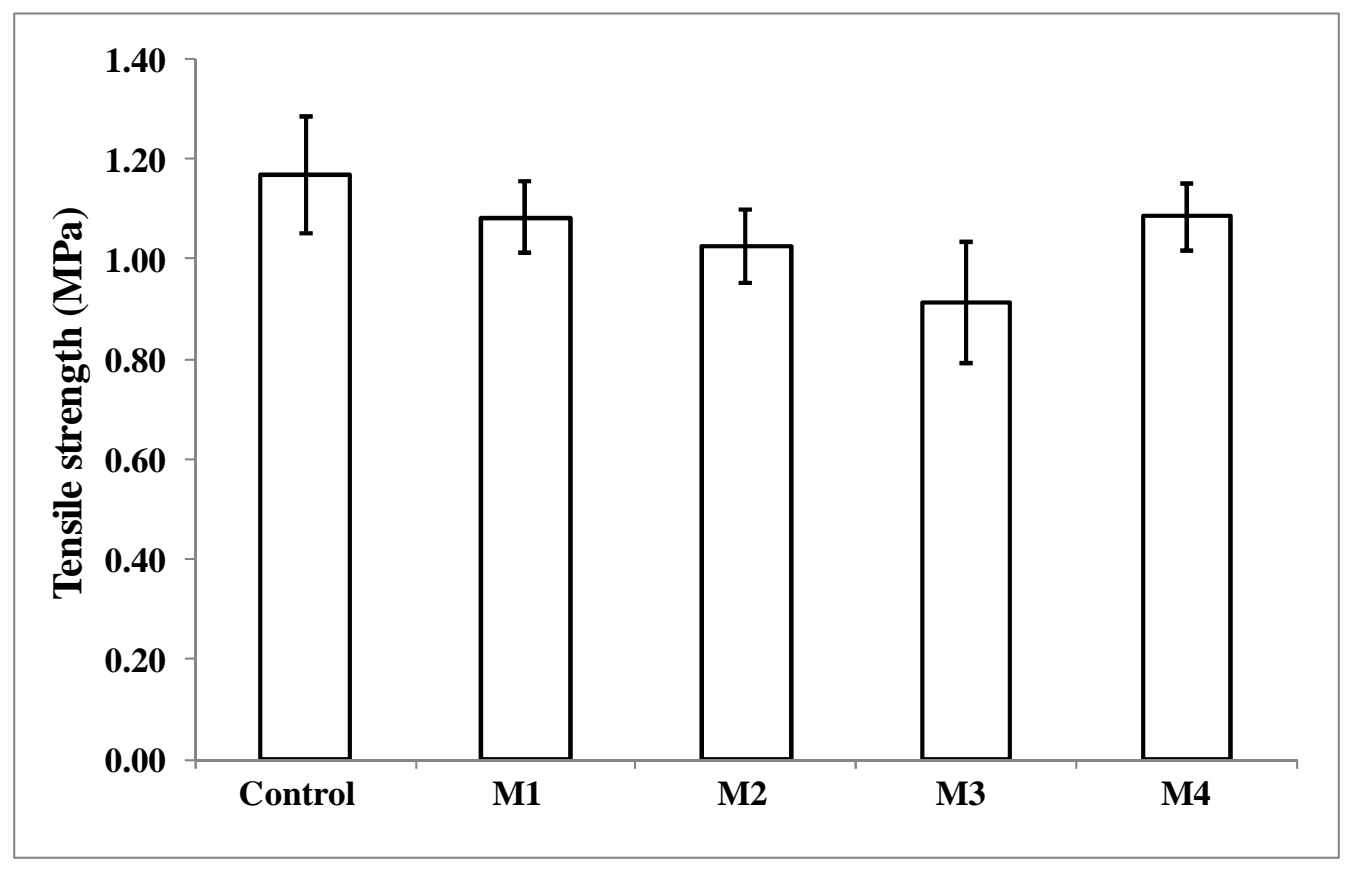

Figure 8: Tensile strength of vulcanized products.

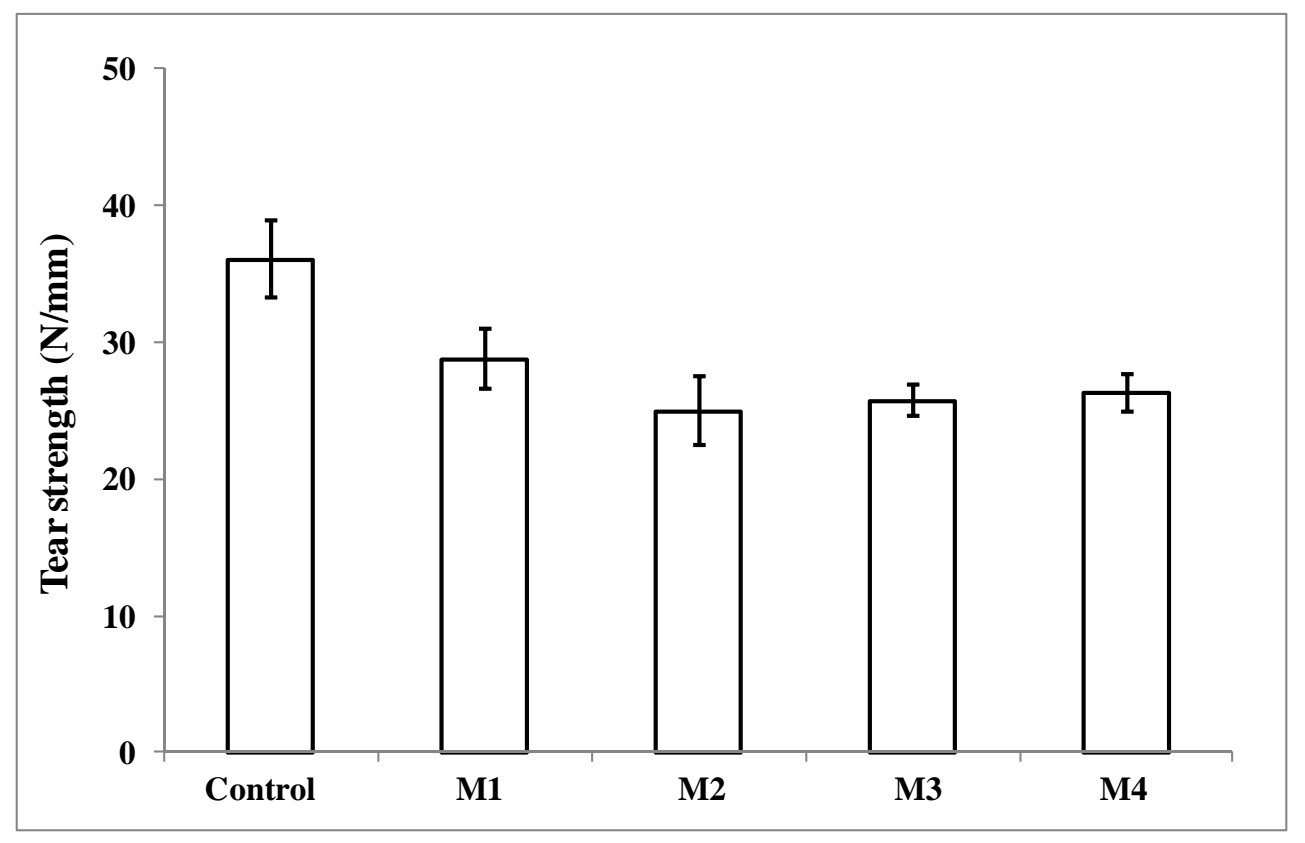

Figure 9: Tear strength of vulcanized products. 


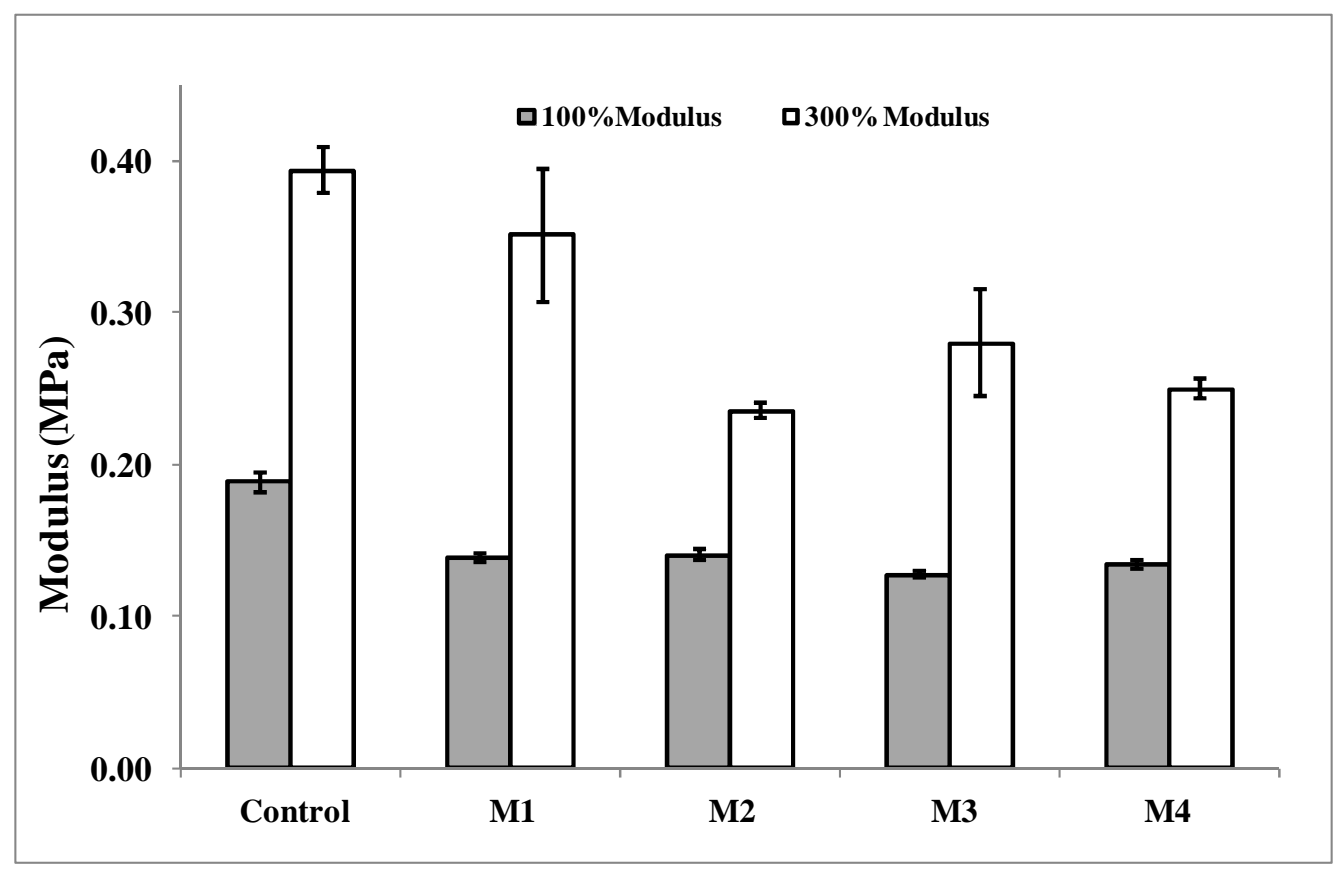

Figure 10: Modulus of vulcanized products.

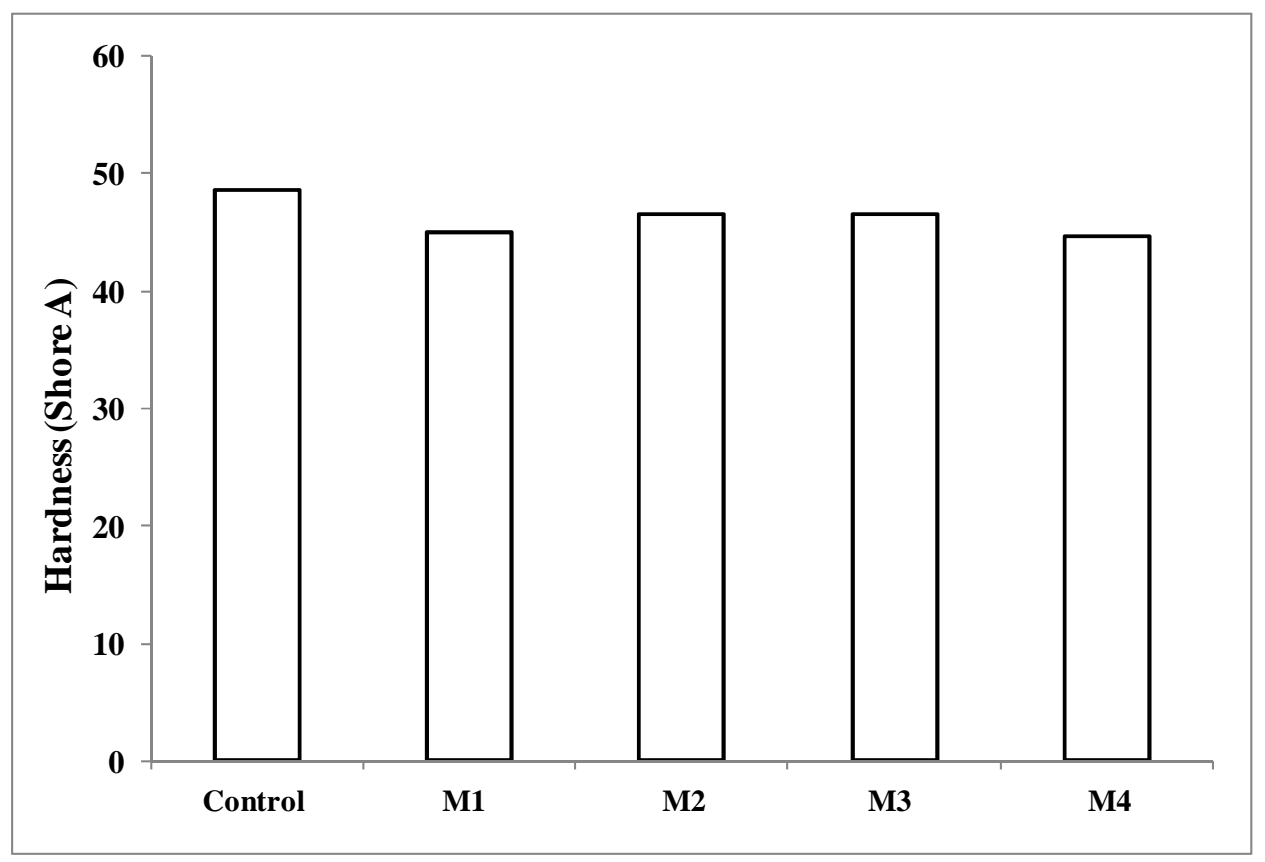

Figure 11: Hardness properties of vulcanized products. 


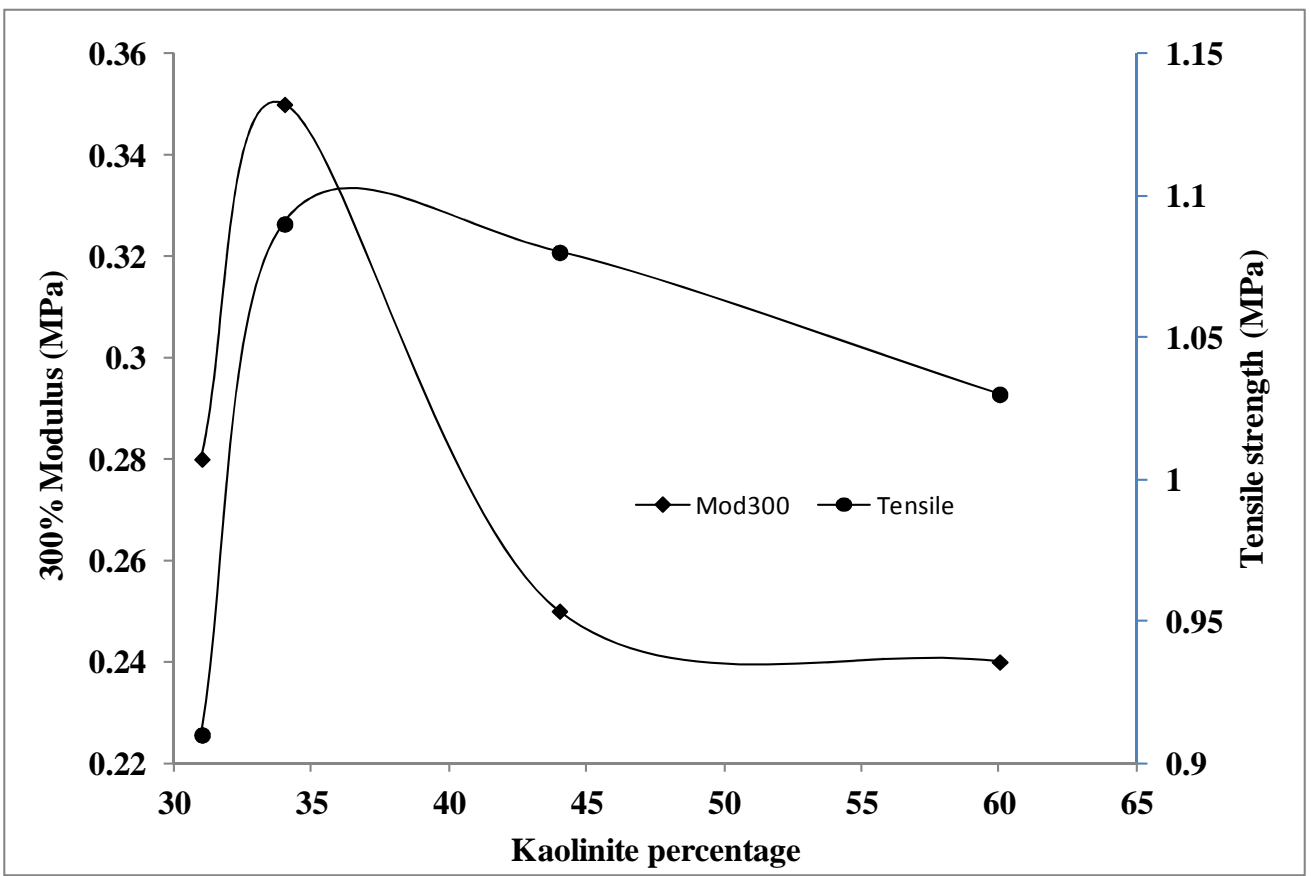

Figure 12: Evolution of Modulus and tensile with kaolinite percentage.

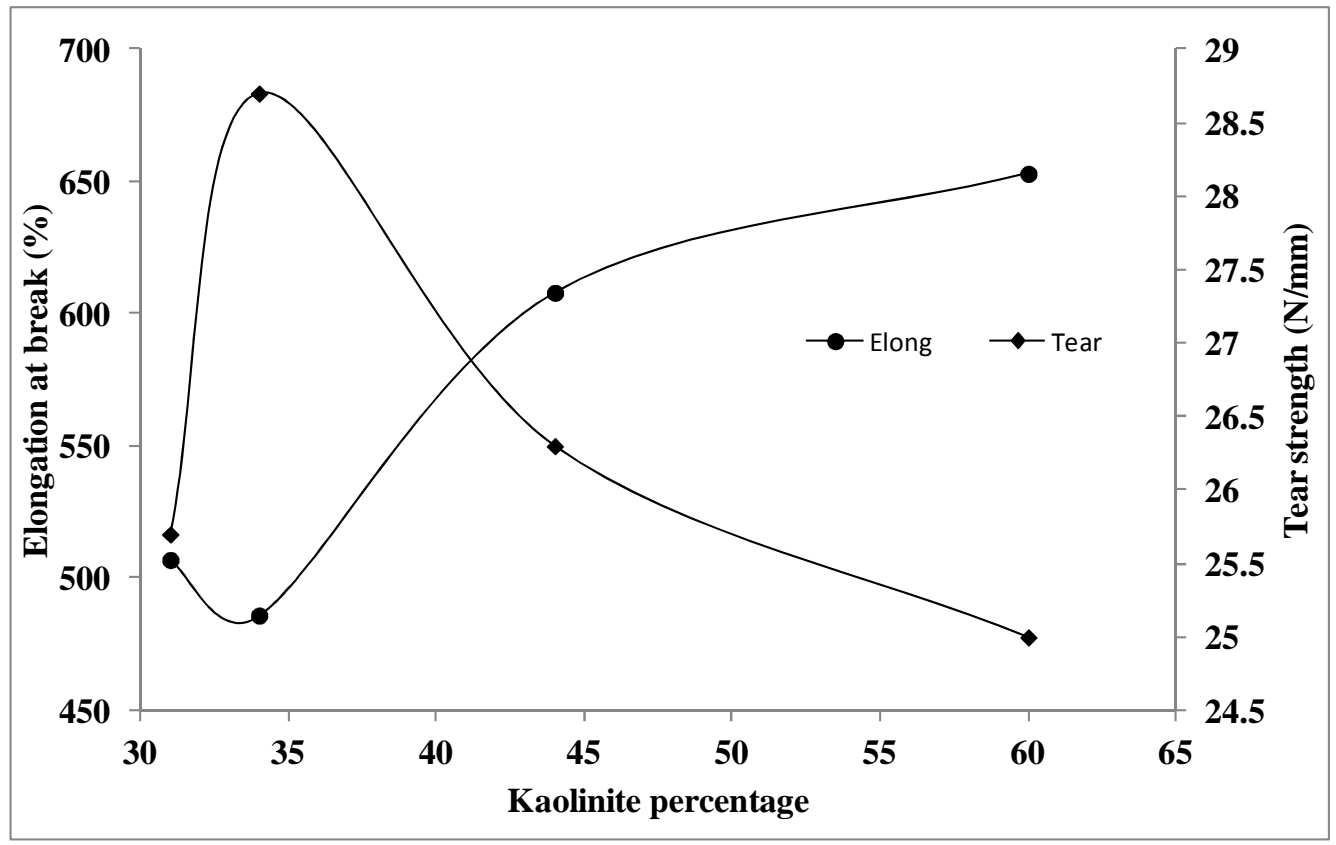

Figure 13: Elongation at break and tear with kaolinite percentage. 
Table 2-a: Chemical composition of major element of materials.

\begin{tabular}{lcccccccccccc}
\hline $\begin{array}{l}\text { Oxides } \\
(\%)\end{array}$ & $\mathbf{S i O}_{2}$ & $\mathrm{Al}_{\mathbf{2}} \mathbf{O}_{\mathbf{3}}$ & $\mathbf{F e}_{\mathbf{2}} \mathbf{O}_{\mathbf{3}}$ & $\mathrm{MnO}$ & $\mathbf{M g O}$ & $\mathbf{C a O}$ & $\mathbf{N a}_{\mathbf{2}} \mathbf{O}$ & $\mathbf{K}_{\mathbf{2}} \mathbf{O}$ & $\mathbf{T i O}_{\mathbf{2}}$ & $\mathbf{P}_{\mathbf{2}} \mathbf{O}_{\mathbf{5}}$ & L.O.I & Total \\
\hline $\mathrm{M} 1$ & 71.42 & 19.5 & 0.4 & 0.0 & 0.23 & $<\mathrm{LD}$ & 0.36 & 1.68 & 0.82 & $<\mathrm{LD}$ & 5.30 & 99.7 \\
$\mathrm{M} 2$ & 53.88 & 29.51 & 3.71 & 0.01 & 0.45 & 0.04 & 0.04 & 1.52 & 0.46 & $<\mathrm{LD}$ & 10.60 & 100.21 \\
$\mathrm{M} 3$ & 72.75 & 19.06 & 0.35 & $<\mathrm{LD}$ & 0.25 & $<\mathrm{LD}$ & 0.73 & 1.94 & 0.82 & $<\mathrm{LD}$ & 4.58 & 100.08 \\
$\mathrm{M} 4$ & 70.75 & 20.12 & 0.73 & $<\mathrm{LD}$ & 0.12 & $<\mathrm{LD}$ & 0.17 & 0.66 & 0.93 & $<\mathrm{LD}$ & 6.66 & 100.19 \\
\hline
\end{tabular}

Table 2-b: Chemical composition of trace element of materials.

\begin{tabular}{lccccccccc}
\hline Elements (ppm) & $\mathbf{T h}$ & $\mathbf{T m}$ & $\mathbf{U}$ & $\mathbf{V}$ & $\mathbf{W}$ & $\mathbf{Y}$ & $\mathbf{Y b}$ & $\mathbf{Z n}$ & $\mathbf{Z r}$ \\
\hline M1 & 2.633 & 0.31 & 0.836 & 137.7 & 0.598 & 19.15 & 2.121 & $<$ L.D. & 147.4 \\
M2 & 2.113 & 0.119 & 0.918 & 50.53 & 0.332 & 6.958 & 0.877 & 20.81 & 129.2 \\
M3 & 4.29 & 0.568 & 2.084 & 113.8 & 0.804 & 37.99 & 3.891 & $<$ L.D. & 214.6 \\
M4 & 3.585 & 0.352 & 1.113 & 126.2 & 0.662 & 23.36 & 2.394 & $<$ L.D. & 256.4 \\
\hline <LD : less than the detection limit, L.O.I : loss on ignition
\end{tabular}

$<$ LD : less than the detection limit, L.O.I : loss on ignition

Table 3: Mineralogical composition of raw materials.

\begin{tabular}{|c|c|c|c|c|c|}
\hline \multirow{2}{*}{ Samples } & \multicolumn{4}{|c|}{ Content $(\%)$} & \multirow[b]{2}{*}{ Total } \\
\hline & Kaolinite & Quartz & Illite & Goethite & \\
\hline M1 & 34 & 49 & 15 & - & 98 \\
\hline M2 & 60 & 20 & 13 & 4 & 97 \\
\hline M3 & 31 & 50 & 17 & - & 98 \\
\hline M4 & 44 & 48 & 6 & - & 98 \\
\hline
\end{tabular}

Table 4: Cure characteristic parameters.

\begin{tabular}{lccccc}
\hline Properties & $\mathbf{M}_{\mathbf{L}}(\mathbf{d N m})$ & $\mathbf{M}_{\mathbf{H}}(\mathbf{d N m})$ & $\Delta \mathbf{M}(\mathbf{d N m})$ & $\mathbf{t}_{\mathbf{s 5}}(\mathbf{m i n})$ & $\mathbf{t}_{\mathbf{c 9 0}}(\mathbf{m i n})$ \\
\hline Control & 14.93 & 51.27 & 36.34 & 1.87 & 2.72 \\
M1 & 15.06 & 55.01 & 39.95 & 1.6 & 2.37 \\
M2 & 13.64 & 53.75 & 40.11 & 1.72 & 2.43 \\
M3 & 15.25 & 55.73 & 40.48 & 1.57 & 2.33 \\
M4 & 16.33 & 57.42 & 41.09 & 1.55 & 2.32 \\
\hline
\end{tabular}

\section{Conclusion}

The samples studied in the intention to be used in reinforcing of rubber compounds are essential kaolinite, illite and quartz. The different tests on the mechanical and rheological proprieties show that they cannot be used such as in the reinforcing of rubber compounds. They present a behavior in general, slightly lower than that of the reference. It is then necessary to pretreat the different samples to eliminate the impurities and to reduce the size of particle which can contribute to improve the reinforcing properties of the clays. However, the study 
shows that the mechanical properties depend in general, on the amount of kaolinite. After $34 \%$ of kaolinite, the different properties become less and less better.

\section{REFERENCES}

Joshi M, Biswas D, Sarvanan A, Roli P, Mukhopadhaya R. 2012. Nylon 6 / Clay Nanocomposite Filaments and Their Cords. J. Appl. Polym. Sci., 125: $224-$ 234.

Lucia C, Paolo S, Giovanna C, Roberta B, Aldo P. 2012. The clay mineral modifier as the key to steer the properties of rubber nanocomposites. Appl. Clay. Sci., 61: 14 -21 .

Rattanasom N, Prasertsri S. 2009. Relationship among mechanical properties, heat ageing resistance, cut growth behaviour and morphology in natural rubber: Partial replacement of clay with various types of carbon black at similar hardness level. Polymer. Testing., 28: $270-276$.

Saritha A, Kuruvilla J, Sabu T, Muraleekrishnan R. 2012. The Role of Surfactant Type and Modifier Concentration in Tailoring the Properties of Chlorobutyl Rubber/Organo Clay Nanocomposites. J. Appl. Polym. Sci., 124: 4590 - 4597.

Sepehri A, Razzaghi-Kashani M, Ghoreishy MHR. 2012. Vulcanization Kinetics of
Butyl Rubber-Clay NanoComposites and Its Dependence on Clay Microstructure. J. Appl. Polym. Sci., 125: 204 - 212.

Valadares LF, Leite CAP, Galembeck F. 2006. Preparation of natural rubber montmorillonite nanocomposite in aqueous medium: evidence for polymerplatelet adhesion. Polymer., 47: 672 678.

Xiaohui W, Yiqing W, Jun L, Shaojian H, Liqun Z. 2012. Improved Crack Growth Resistance and Its Molecular Origin of Natural Rubber/Carbon Black by Nanodispersed Clay. Polym. Eng. Sci., 1027 - 1036.

Yehia AA, Akelah AM, Rehab A, El Sabbagh SH, El Nashar DE, Korien AA. 2012. Evaluation of clay hybrid nanocomposites of different chain length as reinforcing agent for natural and synthetic rubbers. Materials and Design., 33: $11-19$

Yijing N, Lianglian Q, Guangsu H, Bingyin W, Gengsheng W, Jinrong W. 2010. Improved resistance to crack growth of natural rubber by the inclusion of nanoclay. Polym. Adv. Techn., 23, 85 91.

Yvon J, Garin P, Delon JF, Cases JM. 1982. Valorisation des argiles kaolinitiques des Charentes dans le caoutchouc naturel. Bull. Minér., 105: 431-437. 